\title{
Autonomous Pinniped Environmental Samplers: Using Instrumented Animals as Oceanographic Data Collectors
}

\author{
George W. Boehlert,* Daniel P. Costa, ${ }^{+}$Daniel E. Crocker, ${ }^{\#}$ Phaedra Green,* Todd O’Brien, ${ }^{\circledR}$ \\ Syd Levitus, @ AND Burney J. Le Boeuf ${ }^{+}$ \\ *NOAA/NMFS, Southwest Fisheries Science Center, Pacific Fisheries Environmental Laboratory, Pacific Grove, California \\ ${ }^{+}$Department of Biology, University of California, Santa Cruz, Santa Cruz, California

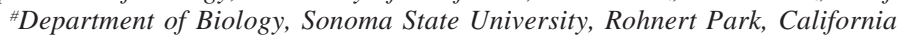 \\ ${ }^{\circledR}$ NOAA/NESDIS National Oceanographic Data Center, Silver Spring, Maryland
}

(Manuscript received 7 September 2000, in final form 16 May 2001)

\section{ABSTRACT}

\begin{abstract}
Data-recording tags applied to marine animals store data for later retrieval and can return valuable information on animal behavior and ecology, including habitat preference, physiology, and movement patterns, as well as environmental data. If properly instrumented, calibrated, and archived, data from these tags can add to the oceanographic datastream for parts of the ocean where data are sparse or lacking. Such data, from northern elephant seals instrumented with time-temperature-depth recorders (TTDR) and ARGOS platform terminal transmitters, is examined in this study. Northern elephant seals range widely over the northeastern Pacific on long foraging trips. The seals dive continuously on these trips to depths of 400-600 m.

Between March 1998 and March 1999, six female and three male elephant seals were tagged in central California and data were collected during subsequent foraging trips. Temperature and depth were measured and stored every $30 \mathrm{~s}$ and retrieved after the animals returned to the rookery months later. Portions of the track where both ARGOS and TTDR data were available from these nine animals averaged $4634 \mathrm{~km}$ over 67 days with 2.4 ARGOS positions per day. Mean dive duration was $20 \mathrm{~min}$ and mean dive depth was $428 \mathrm{~m}$. A comparison of temperature profiles from seal TTDR with Global Temperature-Salinity Profile Program (GTSPP) subsurface data showed very good agreement, as did surface temperatures to other sources of SST. Quality control of the data and entry into the World Ocean Database (WOD) is described. A total of 75665 autonomous pinniped bathythermograph (APBT) profiles over the $41702 \mathrm{~km}$ of seal trackline were added to the WOD.

Biological autonomous sampling systems have immense potential to contribute oceanographic data in a costeffective manner. The northern elephant seal represents but one species covering portions of the northeast Pacific Ocean. Research programs presently exist on a variety of species, including southern elephant seals and other pinnipeds, tunas and billfish, sharks, seabirds, marine turtles, and whales. With improving technology, such tags will be applied to even more marine animals and the approach described here can be applied to other species to improve ocean data availability.
\end{abstract}

\section{Introduction}

The ability to conduct research on the behavior and movements of oceanic animals has been markedly improved by miniaturization of electronic components and sensors. Electronic tags have been used in an expanding range of biological applications. Passive integrated transponder tags, for example, provide identification of individual animals but relatively little else (Brannas et al. 1994). Telemetering tags, using either acoustic or radio frequency communication, transmit data in real time and can be used to track or monitor animals directly or with remote recording stations (Brill et al. 1995). Archival tags, which may have various sensors, record and store

Corresponding author address: Dr. George Boehlert, NOAA, Southwest Fisheries Science Center, Pacific Fisheries Environmental Laboratory, 1352 Lighthouse Ave., Pacific Grove, CA 93950-2097. E-mail: gboehlert@pfeg.noaa.gov data for later retrieval after the animal is recaptured. These small electronic tags, with their continually improving measurement accuracy, can return valuable information, including habitat preferences, physiological data, environmental data, and movement patterns, and their use has been expanding to a wide variety of animals (Boehlert 1997).

If properly instrumented, calibrated, and archived, selected information from such tags has great potential to add to the oceanographic datastream for parts of the ocean where data are sparse or lacking (Costa 1993; McCafferty et al. 1999; Campagna et al. 2000; Koudil et al. 2000). Still, two issues have hindered the widespread use of such "biological autonomous" collection of oceanographic data. First, unless data are telemetered by satellite, the animal must be recaptured in order to make use of the data contained in the tag. Adequate recapture rates require deployment either in large num- 


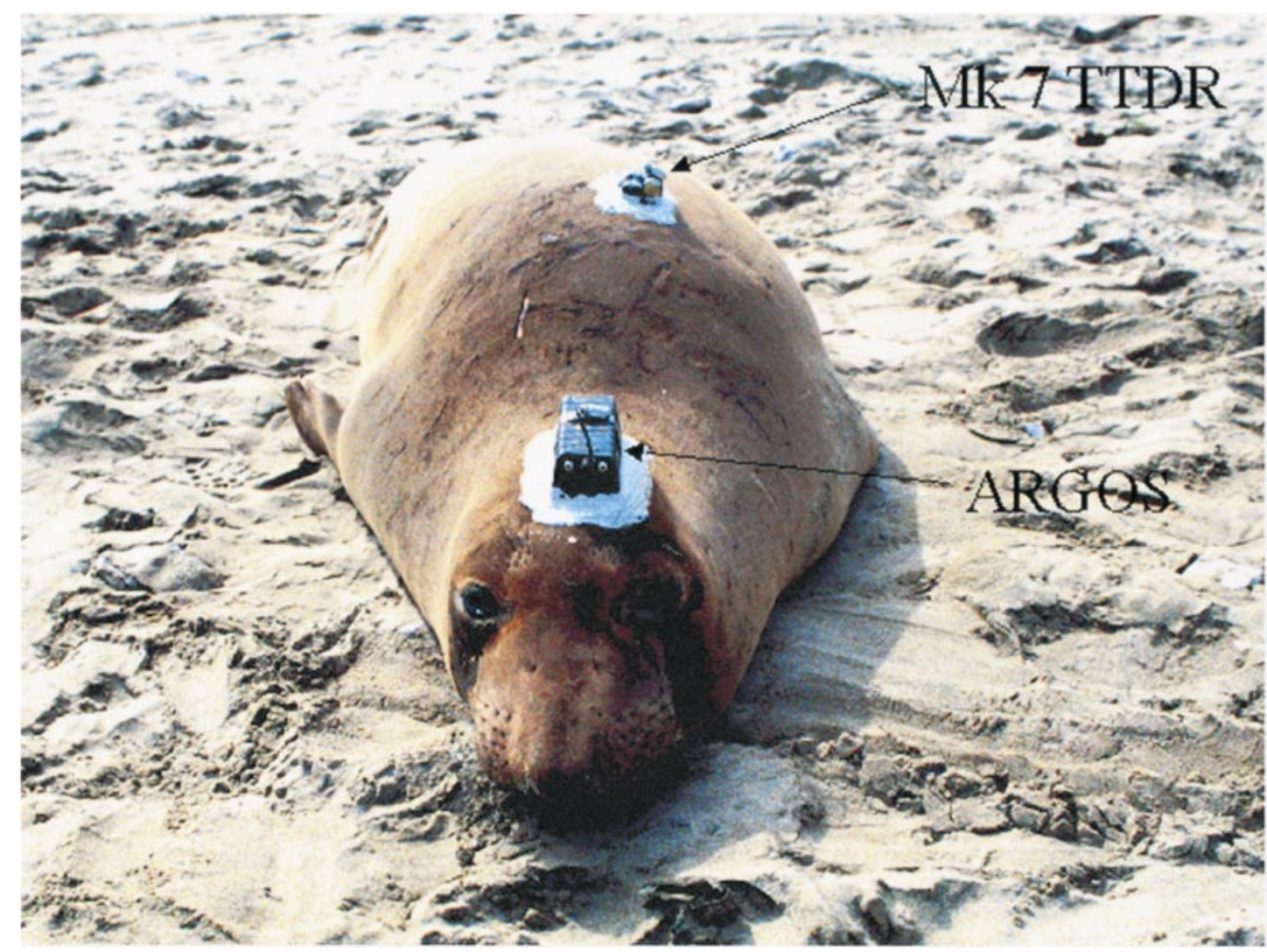

FIG. 1. Adult female elephant seal with ARGOS satellite transmitter and Mk 7 TTDR attached. Observations of behavior at sea suggest that only the head is out of the water, so the location of the TTDR on the back means that it is submerged during surface behavior and, thus, temperature measurements reflect ocean temperature.

bers (with concomitant expense) or on animals with high likelihood of return. Return rates have been relatively high for animals with homing behavior and low mortality rates, such as marine mammals (Le Boeuf et al. 2000; McCafferty et al. 1999; Lagerquist et al. 2000) or sea turtles (Polovina et al. 2000). Fish have moderately high mortality rates. To date, the greatest successes have been with high value species, such as salmon (Walker et al. 2000) or bluefin tuna (Block et al. 1998). In this case, high recapture probabilities in fisheries result in moderately high return rates.

The second problem is determination of the position where data were collected; for many tags, geographic position is poor or lacking. Tags able to record geoposition are generally too large except for large and robust animals. Data-recording tags placed on many fish, for example, have had no mechanism to determine position, with the exception of tagging and recovery locations (Walker et al. 2000). Archival tags with light sensors that estimate longitude from time of sunrise or sunset and latitude from day length have been applied to several species (Wilson et al. 1998; Tuck et al. 1999). Locations derived from these tags have relatively large theoretical variances. Under practical application, where animals may reside at different depths and weather sys- tems may impact measured light intensity, the error may be even greater (Welch and Eveson 1999). A more recent development, which partially addresses both return rate and location information, is the "pop-up" tag, programmed to release from the animal after a preset time and then to transmit its data to a satellite (Block et al. 1998). While the data volume transmitted by these tags is limited to a recent series of temperature-depth profiles, the technology is improving; moreover, the tags can be programmed to continue transmitting SST data for 30 days (Lutcavage et al. 1999).

Larger animals, with a lower mortality rate and higher likelihood of return, are able to carry a larger instrument package. Elephant seals (Mirounga angustirostris), for example, offer a unique system to carry instrumentation and to collect environmental information with high value from an oceanographic standpoint (Costa 1993; Le Boeuf et al. 2000). From California rookeries, this species ranges widely over the northeastern Pacific on foraging trips that last from 2 to 9 months. Migration patterns differ between the sexes; females may migrate throughout the northeastern Pacific, while males migrate to destinations along the continental margin from coastal Oregon north to the Aleutian Islands. Females are at sea on average 3 months during the spring migration and 7 
months during the summer-fall migration. Adult females increase their body mass during both migrations, the second of which includes gestation. Northern elephant seals dive continuously, exhibiting extremely long duration dives $($ mean $=22 \mathrm{~min}, \max =120 \mathrm{~min})$ with short surface intervals (1-3 min). Dives are routinely to $600 \mathrm{~m}$, but can be as deep as $1600 \mathrm{~m}$. Unlike other diving pinnipeds, elephant seals do not dive in bouts; extended periods at the surface are extremely rare (Le Boeuf et al. 1986, 2000; Costa 1993).

Animals from the above studies are instrumented with time-temperature-depth recorders and ARGOS platform terminal transmitters. Although large volumes of environmental information have been collected during the tagging studies on these animals, the principal purpose has been to evaluate the behavior of the seals rather than ocean conditions (Costa 1993). Thus, the objectives of this paper are to evaluate existing temperature profiles taken from instruments attached to northern elephant seals from throughout the central and eastern North Pacific, to add these records to the National Oceanographic and Atmospheric Administration (NOAA) World Ocean Database (WOD; Levitus et al. 1998), and to provide an example for other biological researchers to collect data in formats and with approaches consistent with submission to common physical databases.

\section{Methods}

\section{a. Tagging}

All elephant seal tagging occurred at the Año Nuevo rookery in Central California $\left(37.11^{\circ} \mathrm{N}, 122.33^{\circ} \mathrm{W}\right)$. Data on diving behavior, ranging and migration, and distribution of elephant seals by time of year, sex, and age, have been collected since 1990. Tagging techniques and decisions on timing of tagging (to assure temporal proximity to departure date) were based on past experience. Tagging procedures, animal handling, and tag recovery procedures are fully described in Le Boeuf et al. (2000) and will not be repeated in detail here. It should be noted, however, that the procedures are conducted under research permits from the U.S. National Marine Fisheries Service and are also reviewed by an Institutional Animal Research Care and Use Committee. They are not deemed to be harmful to these animals.

\section{b. Instrumentation and data handling}

\section{1) ARGOS TRANSMITTERS}

Half-watt satellite platform transmitter terminals (PTT; Model ST-6, Telonics, Mesa, Arizona) were affixed near the animal's head using epoxy (Fig. 1), which is shed during molting after the animal returns from its migration. The antenna was oriented so as to be out of the water when the seal surfaced. The PTT transmitted every $34 \mathrm{~s}$ while the animals were at the surface. Be- cause of the small antenna, the relatively low power of the transmitter, and the limited surface time, each surface period will not provide a position fix. Consequently, positions were determined using the ARGOS system with auxiliary location processing, wherein lower quality locations (class A and B) are still calculated and reported (Taillade 1992). Estimates of mean errors were also based on animals hauled out at Año Nuevo. The rookery is basically a $1-\mathrm{km}$ bight and the location in the center of the bight, determined by global positioning system (GPS), was used as a comparison with the ARGOS position.

Locations were further filtered using standard methods used by marine mammal tracking studies (see McConnell et al. 1992). This method starts with the time the animal enters the water at Año Nuevo and iteratively compares the distance to each succeeding ARGOS position. The resulting transit rates are compared to a reasonable maximum transit speed for the elephant seals. For this project we used a conservative $3.0 \mathrm{~m} \mathrm{~s}^{-1}$ transit speed. Each subsequent hit is either accepted or rejected. When the filter rejects a location $[\operatorname{LOC}(x)]$, its location quality and IQ (an inverse index of residual frequency error and frequency drift; i.e., high IQ equals a high confidence in signal characteristics) are compared to the preceding location $[\operatorname{LOC}(x-1)]$. If the rejected location $[\operatorname{LOC}(x)]$ was of higher quality or same quality but higher IQ than the preceding hit $[\operatorname{LOC}(x-1)]$, the alternative of rejecting the previous hit was considered. If rejecting the previously accepted location $[\operatorname{LOC}(x-1)]$ results in reasonable transit speeds from the previous hit $[\operatorname{LOC}(x-2)]$ to the current higher quality location, $\operatorname{LOC}(x)$ was accepted and LOC $(x-1)$ was rejected. This process was continued until the end of the location data for each animal.

We also performed empirical tests to determine the uncertainties introduced into the position estimates caused by variable times between fixes. This is difficult, however, because seals are actively moving in different directions with time. Thus, deviations from a straight trackline are compounded by the directional behavior exhibited by the animal. We analyzed the ARGOS track data by sequentially dropping out intermediate fix positions, estimating the location of the intermediate point by linear interpolation, and then taking the difference (in $\mathrm{km}$ ) from the actual ARGOS position. Given three ARGOS position fixes $P_{(i)}$, $P_{(i+1)}, P_{(i+2)}$, a straight line was drawn from $P_{(i)}$ to $P_{(i+2)}$; based upon the elapsed time to the intermediate position, $P_{(i+1) \text { est }}$ was calculated, and the distance between $P_{(i+1)}$ and $P_{(i+1) \text { est }}$ is an estimate of the deviation from the track. This was done iteratively for all tracks in the study and the results related to time and distance between ARGOS positions.

\section{2) TiME-TEMPERATURE-DEPTH RECORDERS (TTDRs)}

Temperature and depth were measured with Mk 3 data recording tags (Wildlife Computers, Seattle, Washing- 
ton). This instrument has a temperature resolution of $0.1^{\circ} \mathrm{C}$ and accuracy of $0.5^{\circ} \mathrm{C}$. All of the TTDRs had a manufacturer's stated minimum recording temperature of $4.8^{\circ} \mathrm{C}$, although one instrument showed truncation of data records at $5^{\circ} \mathrm{C}$. This TTDR was carried by two animals in the dataset. Minimal temperatures recorded were examined for each animal; if evidence of truncation was noted, records at and below this temperature were discarded. Because the thermistor was contained in the housing on this model, temperature response was delayed; the factory-estimated time constant was $1 \mathrm{~min}$. Water bath experiments performed on units prior to deployment suggested that thermal characteristics of the housings on all tags used were close to identical. To evaluate the time constant for correcting temperature from the field, an instrument was set to record at 5-s intervals (those deployed on animals were set to record every 30 s) and lowered on a wire along with a SeaBird conductivity-temperature-depth (CTD) recorder. The lowering and retrieval speed were similar to that of seal dives. The two data records (Mk 3 and CTD) were aligned and differenced at each measurement from the Mk 3. This was done with successive 5-s time offsets (no offset, $5 \mathrm{~s}, 10 \mathrm{~s}, 15 \mathrm{~s}, \ldots, 60 \mathrm{~s}$ ). The time constant chosen for application to the field was that with the lowest sum of absolute values of the differenced data.

Temperature calibration curves were determined for each TTDR using a water bath and a thermistor $\left(0.01^{\circ} \mathrm{C}\right)$ datalogger. The resultant linear regressions were used to correct raw temperature data. Slopes ranged from 0.97 to 1.01 ; intercepts ranged from -0.21 to 0.31 . Two TTDRs yielded nonlinear calibration curves, and data from those animals were not included in the dataset. The pressure transducers on the TTDRs were calibrated prior to deployment using a pressure station. All Mk 3 TTDRs used have two transducer channels. In order to increase accuracy on shallower dives TTDRs were programmed to use channel 1 for depths $<450 \mathrm{~m}$ (with accuracy $<2 \mathrm{~m}$ ) and channel 2 for depths $>450 \mathrm{~m}$ (with accuracy $<4 \mathrm{~m})$.

In the field, TTDRs were attached to the animals' pelage on the dorsal midline above the shoulders using epoxy (Fig. 1). TTDR data were recorded in memory every $30 \mathrm{~s}$ and retrieved after the animals returned to the rookery months later. A potential problem noted by McCafferty et al. (1999) was that solar insolation on the tags (as the seals remained at the surface) raised the recorded temperature above the ambient SST. Elephant seals dive continuously, however, with surface intervals typically less than $3 \mathrm{~min}$; during that time, only the head breaks the surface, with the TTDR remaining submerged (Le Boeuf and Crocker 1996). Thus, effects of solar insolation on recorded temperature were not deemed to be a problem.

\section{3) DAtA HANDLing}

Upon return from the field, data files were modified using a program from the manufacturer (Wildlife Com- puter, Zoc.exe version 1.27) to correct zero offset in depth. This program allows visual inspection of all dives and correction for surface drift. Since the animal returns to the surface after each dive, offset is set accordingly for each dive. Some records do not require an offset correction, some records have a constant offset correction for the entire file, and some records drift and require several offset corrections. Data were also offset by 30 $\mathrm{s}$ to accommodate the time lag described above. Two data files for each animal were available, one with timetemperature-depth and another with time and location from the ARGOS fixes. In most animals, there were periods where TTDR and/or ARGOS data were lacking, and these periods were excluded from further consideration in this study. Data from the two files were aligned; the seal temperature data have roughly 2880 points per day, whereas only 2-3 ARGOS locations are available per day. After temporally aligning each ARGOS position to its respective TTDR data points, all other TTDR points were assigned a geographic position location through linear interpolation between adjacent ARGOS locations.

The NOAA Ocean Climate Laboratory/National Oceanographic Data Center WOD stores data as individual oceanographic profiles. Each profile has a single position and date (e.g., latitude, longitude, month, day, year, time), and contains depth-dependent variables (e.g., temperature, salinity) sorted from the shallowest to the deepest depth. The seal time series data were processed into the WOD data format. Each seal's depthtemperature times series was divided into "dives." A dive was defined as a data series starting at the surface (depth $=0 \mathrm{~m}$ ) that increases in depth to maximum depth (the bottom of the dive), and then returns to the surface (the end of the dive). Each dive was then split into two profiles: a downcast (all points from the start of the dive to the bottom of the dive), and an upcast (all points from the bottom of the dive to the end of the dive). The cast direction (up/down) was stored, and then the profile was sorted (from shallowest to deepest depth). During the sorting process, repeated depth measurements (periods of horizontal hovering, typically at the surface or bottom of a dive) were removed. The profiles were then run through standard WOD quality control checks [range checks; density, gradient, and inversions checks; annual, seasonal, and monthly standard deviation checks against the WOD98 temperature climatologies (see Conkright et al. 1998)].

For simplicity, the date and calculated position of the first measurement within each upcast or downcast were used for the date and position of that profile. The difference in time since the previous ARGOS fix and until the next ARGOS fix were then calculated and stored. If that profile was the closest profile to an ARGOS fix, it was also assigned an ARGOS quality flag (containing a code for the ARGOS signal quality). 
TABLE 1. Data from northern elephant seals used in the current study. All animals began their tracks in Mar of the year indicated. "Total days tracked" represents the entire time the animals migrated, between departure from the rookery and return. "WOD days tracked" represents only those days where both ARGOS and temperature-depth records were available. The following four columns represent data from only those days, whereas the last two columns are averages from the entire duration of the TTDR recording.

\begin{tabular}{|c|c|c|c|c|c|c|c|c|c|c|}
\hline Seal & Sex & Start date & $\begin{array}{c}\text { Total days } \\
\text { tracked }\end{array}$ & $\begin{array}{c}\text { WOD days } \\
\text { tracked }\end{array}$ & $\begin{array}{l}\text { ARGOS } \\
\text { fixes }\end{array}$ & $\begin{array}{l}\text { Fixes } \\
\text { per day }\end{array}$ & $\begin{array}{c}\text { Transit } \\
\left(\mathrm{km} \mathrm{day}^{-1}\right)\end{array}$ & $\begin{array}{l}\text { Distance } \\
(\mathrm{km})\end{array}$ & $\begin{array}{l}\text { Mean dive } \\
\text { depth (m) }\end{array}$ & $\begin{array}{l}\text { Mean dive } \\
\text { duration } \\
\text { (min) }\end{array}$ \\
\hline Wave & $\mathrm{F}$ & 1998 & 98 & 79.73 & 229 & 2.872 & 64.64 & 5153.8 & 459 & 18.4 \\
\hline Storm & F & 1998 & 64 & 18.63 & 39 & 2.093 & 53.34 & 994.0 & 462 & 22.2 \\
\hline Rain & $\mathrm{F}$ & 1998 & 94 & 73.32 & 197 & 2.687 & 58.26 & 4271.6 & 494 & 21.8 \\
\hline Sun & $\mathrm{F}$ & 1998 & 87 & 63.31 & 237 & 3.743 & 84.98 & 5379.9 & 520 & 18.3 \\
\hline Gale & F & 1998 & 94 & 92.20 & 229 & 2.484 & 63.77 & 5879.3 & 549 & 19.4 \\
\hline Sun2 & F & 1999 & 88 & 88.51 & 383 & 4.327 & 75.11 & 6647.5 & 434 & 18.4 \\
\hline Moose & M & 1997 & 114 & 112.27 & 147 & 1.309 & 69.14 & 7762.1 & 279 & 23.2 \\
\hline Pete & M & 1997 & 120 & 16.33 & 24 & 1.470 & 109.62 & 1790.3 & 366 & 20.8 \\
\hline Bopp & M & 1997 & 99 & 60.70 & 72 & 1.186 & 62.99 & 3823.7 & 291 & 19.9 \\
\hline \multicolumn{11}{|l|}{ Means } \\
\hline Female & & & 87.5 & 69.28 & 219 & 3.03 & 66.68 & 4721.01 & 486.33 & 19.75 \\
\hline Male & & & 111.0 & 63.10 & 81 & 1.32 & 80.58 & 4458.70 & 312.00 & 21.30 \\
\hline Overall & & & 95.3 & 67.22 & 173 & 2.46 & 71.32 & 4633.57 & 428.22 & 20.27 \\
\hline Total & & & 858 & 605.01 & 1557 & & & 41702 & & \\
\hline
\end{tabular}

\section{Results}

The database of northern elephant seal tracks with ARGOS and TTDR data for this study includes six females tagged between March 1998 and March 1999 and three males tagged in March 1997 (Table 1). Collectively, these animals were tracked for a total of 858 days. Animals traveled an average total distance of 6944 $\mathrm{km}$ over an average duration of 95 days, with mean dive

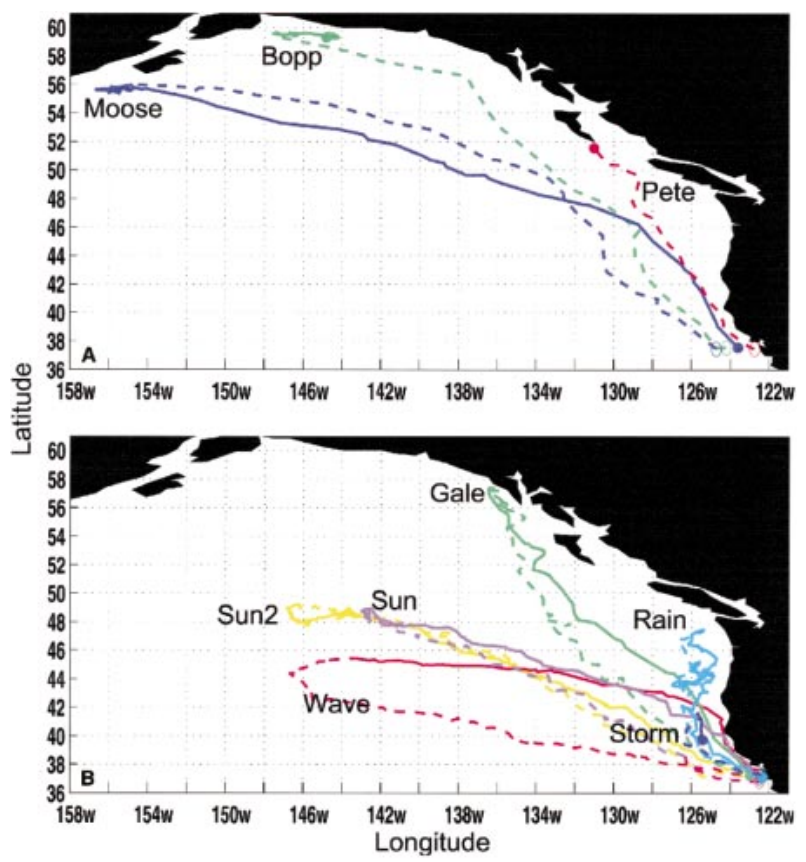

FIG. 2. Tracks of the northern elephant seals from 1997 to 1999 used in the current study. Only those portions of tracks with both TTDR and ARGOS data are shown. (top) Males tracked in 1997; (bottom) females tracked in 1998-99. Note the apparent differences in foraging areas. Outward tracks are dashed lines, return tracks solid. depths of $428 \mathrm{~m}$, each 20.3 min on average. Males typically make shorter duration trips than females, but several of the female trips in these data were during El Niño years and were shorter than normal, apparently due to some effects of an altered foraging environment. Transit speeds of males were greater than that of females. Because much of their foraging is on the continental shelf region, mean dive depths of males is less than that of females. More detailed information on behavior and differences between the sexes is provided in Le Boeuf et al. (2000).

Failure of either the TTDR or ARGOS PTT during these tracks resulted in a reduction of the total number of useful days for the current study to 605 days tracked, a loss of $29 \%$ of the total days at sea (Table 1). Nonetheless, given a 30-s sampling interval, this still represents some 1.74 million temperature-depth pairs with locations. The tracks of the animals in this study (Fig. 2) demonstrate the long-distance movements by northern elephant seals. Females, tracked in 1998-99 show a wide range of patterns, with some animals foraging on the continental slope and others in the open North Pacific. Males tracked in 1997, on the other hand, tend to move rapidly northwest along the coast and spend time foraging at different places along the continental slope (Fig. 2, top). Incomplete tracks for the males associated with loss of data from either instrument are seen clearly in the male data. The track for one male, Moose, is complete from start to finish, whereas tracks for the other two males have only data for the outgoing leg of the track.

The shape of the time-depth curves differs as a function of activity. Le Boeuf et al. (2000) described four types of dives. The three most frequently observed are V-shaped dives (Fig. 3a), which occur mainly during transit, dives with distinct bottom times with multiple 

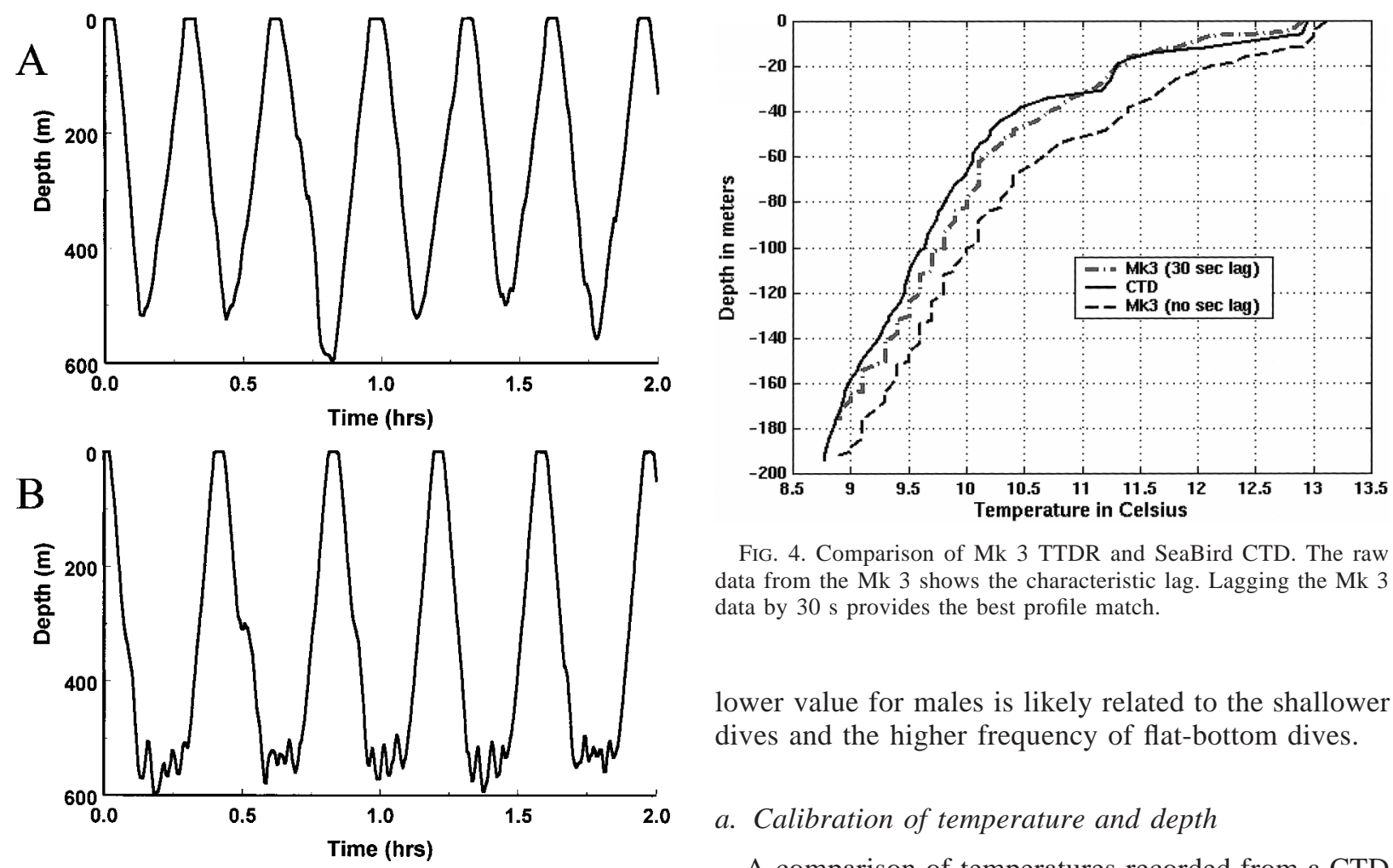

FIg. 4. Comparison of Mk 3 TTDR and SeaBird CTD. The raw data from the Mk 3 shows the characteristic lag. Lagging the Mk 3 data by $30 \mathrm{~s}$ provides the best profile match.

lower value for males is likely related to the shallower dives and the higher frequency of flat-bottom dives.

\section{a. Calibration of temperature and depth}

A comparison of temperatures recorded from a CTD

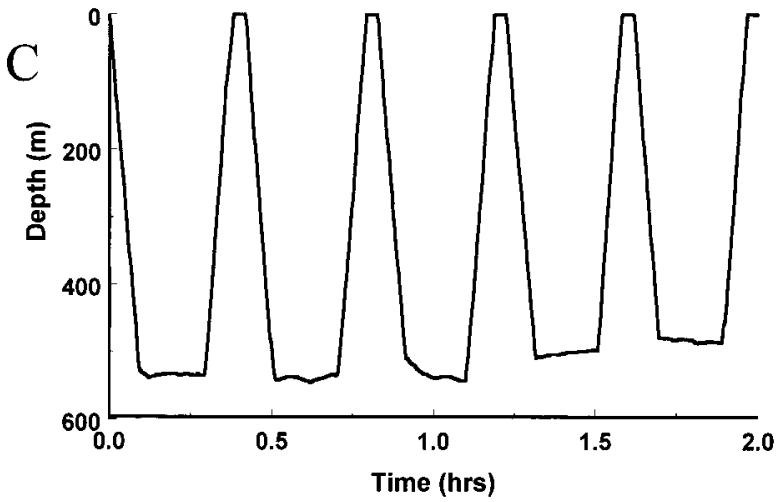

FIG. 3. Typical vertical dive profiles of northern elephant seals. (a) $\mathrm{V}$-shaped dives are characteristic of seals transiting to foraging grounds. (b) Dives with bottom time having vertical excursions are pelagic foraging dives, and (c) dives with flat-bottom times are foraging or transit dives along the continental shelf or slope.

vertical excursions that characterize pelagic foraging (Fig. 3b), and dives with flat bottoms, characteristic of animals transiting or foraging along the continental shelf/slope (Fig. 3c). The frequency of dive type differs between male and female seals and also differs between sexes when animals are in transit or on their focal foraging areas (Le Boeuf et al. 2000). These profiles demonstrate the regularity of the dives and the short surface interval between dives. An approximation of the mean speed of descent or ascent can be calculated based upon mean depths and dive durations (Table 1). Estimates are $0.83 \mathrm{~m} \mathrm{~s}^{-1}$ for females and $0.49 \mathrm{~m} \mathrm{~s}^{-1}$ for males. The and an Mk 3 demonstrates the lag characteristic of this instrument (Fig. 4). With a 5-s sampling interval on the Mk 3, the individual measurement points are clearly evident. Lagging the Mk 3 data by 30 s resulted in a much closer correspondence with the CTD temperatures. A range of lag times from 0-60 s were compared by taking the absolute value of the deviations from each point measured with the Mk 3 to an equivalent temperature at that depth from the CTD. The mean deviations (Fig. 5) were minimal $\left(0.18^{\circ} \mathrm{C}\right)$ at a 30 -s lag, differing from the manufacturer's estimated time constant of $1 \mathrm{~min}$. For data collected from the field, a 30$\mathrm{s}$ lag, representing a shift of one point, was made as a correction to all data.

\section{b. Location accuracy}

The number of ARGOS locations per day ranged from 1.2 to 4.3 , with an average of 2.5 positions per day (Table 1); filtering these data resulted in a loss of 5.8\% of the of the positions. Mean errors were calculated based on animals hauled out at Año Nuevo. The rookery is a $1-\mathrm{km}$ bight and the location in the center of the bight was used as a comparison (GPS position \pm 0.5 $\mathrm{km}$, depending on where the animal was located). Location accuracy for these animals hauled out on the beach, based upon relatively static locations (Table 2), suggests a wide range of mean errors. For comparison, the distribution of ARGOS quality markers for the tracks used in this study is shown in Fig. 6 along with the data from Table 2. The distribution of fixes when 


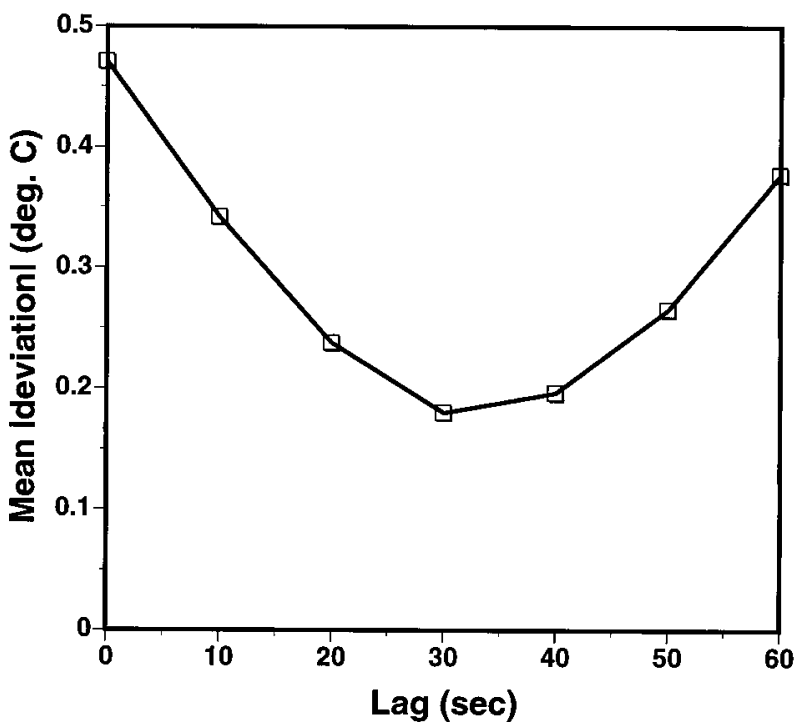

FIG. 5. Comparison of the mean absolute value of the deviation as a function of lag time for the profile in Fig. 4. The 30-s lag has the lowest mean absolute deviation.

the animals are at sea are skewed toward the poorest quality positions compared to when the animals are stationary on land. This is obviously related to a combination of factors, including the duration of surface activity, the antenna being partially submerged during rough seas, and the relatively low power output of the transmitter.

The error associated with ARGOS is compounded by the time (and distance) between ARGOS position fixes during which temperature and depth data continue to be collected. It is further compounded by the behavior of the elephant seals. Because the seals exhibit turning and movement behavior while at sea, linear interpolations between fixes may introduce errors. The empirical tests of iteratively dropping out alternating ARGOS fix positions and then estimating that position based on linear interpolation between the two adjacent positions showed differences between males and females. The average of this deviation was $16.3 \mathrm{~km}$ for the three males and 8.04 $\mathrm{km}$ for the six females. The difference between sexes is probably related to the longer time interval between fixes for males and females-females in this study had

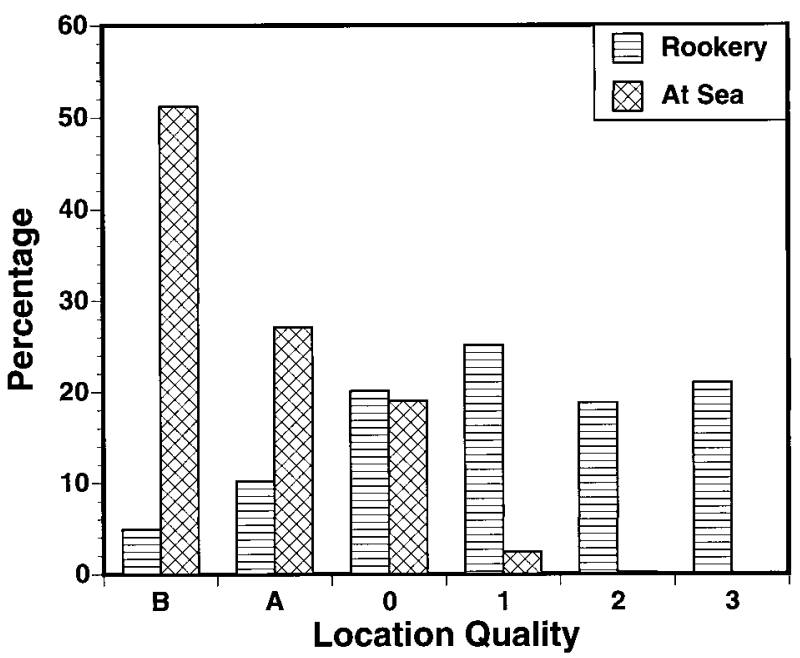

FIG. 6. Distribution of the quality flags for ARGOS fixes from northern elephant seal tracks used in this study compared with positions while animals were on the beach (see Table 2).

ARGOS fixes on average 2.3 times as frequently as males (Table 1). This probably represents a difference in behavior at the surface affecting reception and, therefore, PTT performance. For both males and females, the deviation was linearly related to the time between adjacent fixes; the slopes of the significant regression lines are $7.26 \mathrm{~km} \mathrm{day}^{-1}$ for females and $6.53 \mathrm{~km} \mathrm{day}^{-1}$ for males. In general, however, the averages are consistent with, and probably not distinguishable from, the errors inherent in the ARGOS locations (Table 2).

\section{c. Comparisons with existing temperature data for the North Pacific}

The regularity and depth of dives by these instrumented animals provide an excellent source of surface and subsurface temperature data (Fig. 7) that is not unlike that from towed profiling systems (Aiken et al. 1999). Temperatures recorded by TTDR on northern elephant seals were compared with other sources of temperature data from the North Pacific region. First, the magnitude of data collected by the northern elephant seals is emphasized in the numbers of observations for the time period March-May 1998. Global Temperature-

TABLE 2. Data on the ARGOS satellite fix and location accuracy based upon static trials with animals in the rookery (from Le Boeuf et al. 2000). The actual comparison was subject to an error of $\pm 0.5 \mathrm{~km}$ because the GPS position for comparison was based at the center of the rookery and the animals often move to different parts of the rookery.

\begin{tabular}{|c|c|c|c|c|c|}
\hline $\begin{array}{l}\text { Location } \\
\text { quality }\end{array}$ & $\begin{array}{l}\text { Stated accuracy } \\
\text { (ARGOS) }\end{array}$ & Number & $\begin{array}{l}\text { Error mean } \\
\quad(\mathrm{km})\end{array}$ & $\begin{array}{c}\text { Standard deviation } \\
(\mathrm{km})\end{array}$ & Range (km) \\
\hline 3 & $<150 \mathrm{~m}$ & 338 & 0.8 & 0.1 & $0.3-1.8$ \\
\hline 2 & $150-350 \mathrm{~m}$ & 302 & 1.4 & 0.6 & $0.6-3.4$ \\
\hline 1 & $350-1000 \mathrm{~m}$ & 403 & 2.7 & 2.1 & $0.5-14.9$ \\
\hline 0 & $>1000 \mathrm{~m}$ & 323 & 9.3 & 15.5 & $0.6-78.4$ \\
\hline A & None given & 164 & 28.3 & 50.7 & $0.5-123.1$ \\
\hline B & None given & 78 & 48.4 & 70.4 & $0.7-237.6$ \\
\hline
\end{tabular}




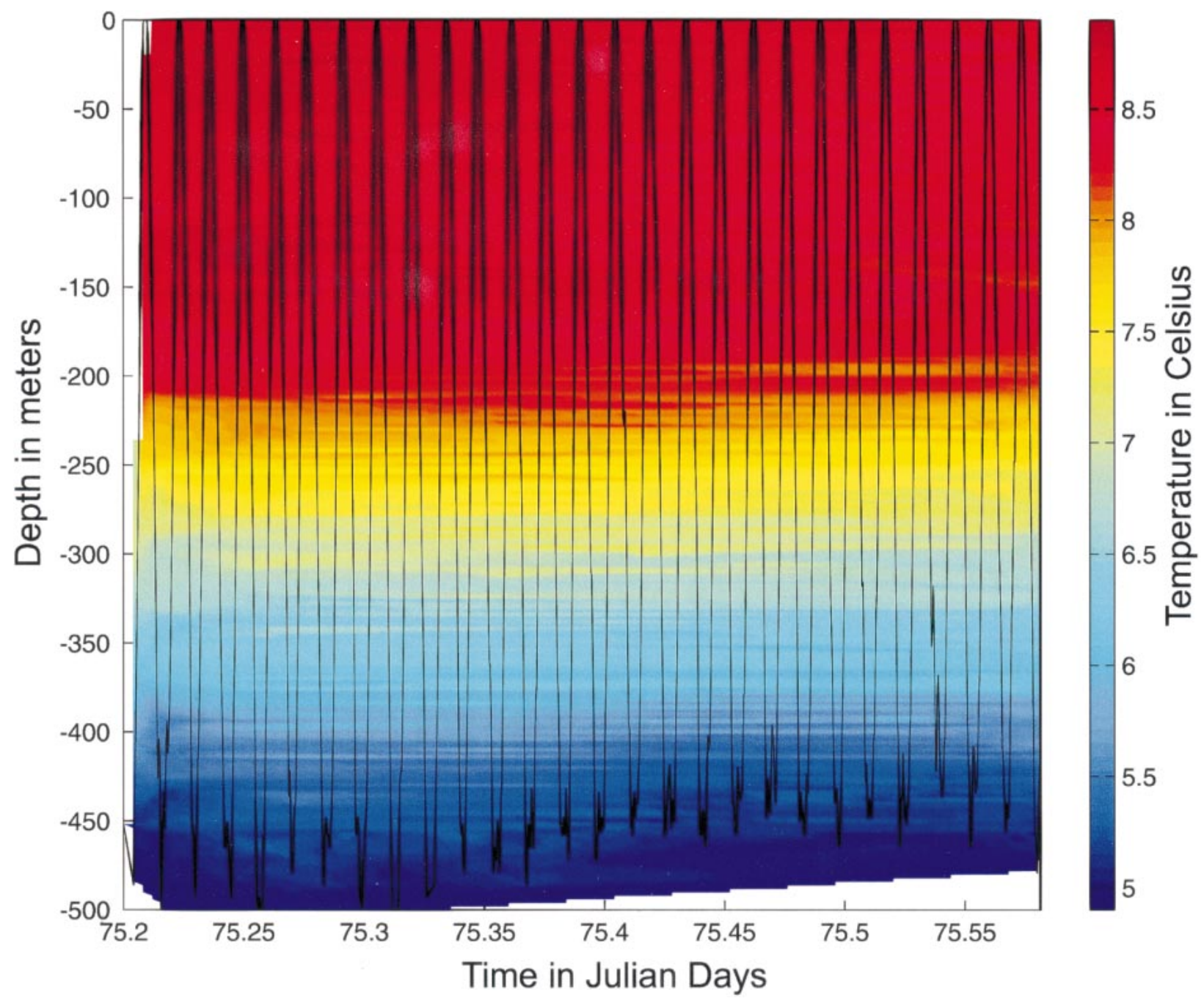

FIG. 7. Dive profiles (line) and thermal structure from a time-temperature-depth recorder on a northern elephant seal from a series of dives over a period of $9.6 \mathrm{~h}$ on $16 \mathrm{Mar} 1998$. The seal was located at $42.58^{\circ} \mathrm{N}, 144.63^{\circ} \mathrm{W}$. Note the regularity of the dives.

Salinity Profile Program (GTSPP) subsurface data (see http://www.nodc.noaa.gov/GTSPP/gtspp-home.html) for this 3-month period show relatively sparse observations; in the area bounded by $36^{\circ} \mathrm{N}$ to the south, $58^{\circ} \mathrm{N}$ to the north, $150^{\circ} \mathrm{W}$ to the west, and the west coast of North America to the east, there were 166 GTSPP observations that measured to at least $10 \mathrm{~m}$. During the same period, five female seals made 22131 dives distributed throughout the region (see Fig. 2). Even combining adjacent dives to generate profiles or subsetting the data in some other way (such as with location quality flags), the available data quantity is substantial.

Given the magnitude of additional subsurface data, concern exists for potentially introducing a false "climate signal" caused by changes in instrumentation. This kind of signal has been observed in the Comprehensive Ocean-Atmosphere Data Set (COADS), for example, in changes from Beaufort scale to anemometer measurements for wind, changes from bucket SST to using en- gine intake measurements on vessels, or where meteorological buoys are added to a given location (Folland and Parker 1990; Roy and Mendelssohn 1998). To examine potential bias or signals introduced in measurements from elephant seals, we compared surface and subsurface temperature measurements from seals with those collected by traditional means. SST data derived from seals (zero-depth temperatures only) were compared with surface Reynolds temperatures (Reynolds and Smith 1994; see http://www.emc.ncep.noaa.gov/ research/cmb/sst_analysis/) over a range of temperatures (Fig. 8). These results show a strong and positive correspondence between these two sources of SST data.

Subsurface data from seals were similarly compared with GTSPP subsurface data (see http://www.nodc.noaa. gov/GTSPP/gtspp-home.html). We took a statistical approach to this analysis, comparing profile data in $1^{\circ}$ square-1-month bins in February through May 1998. 


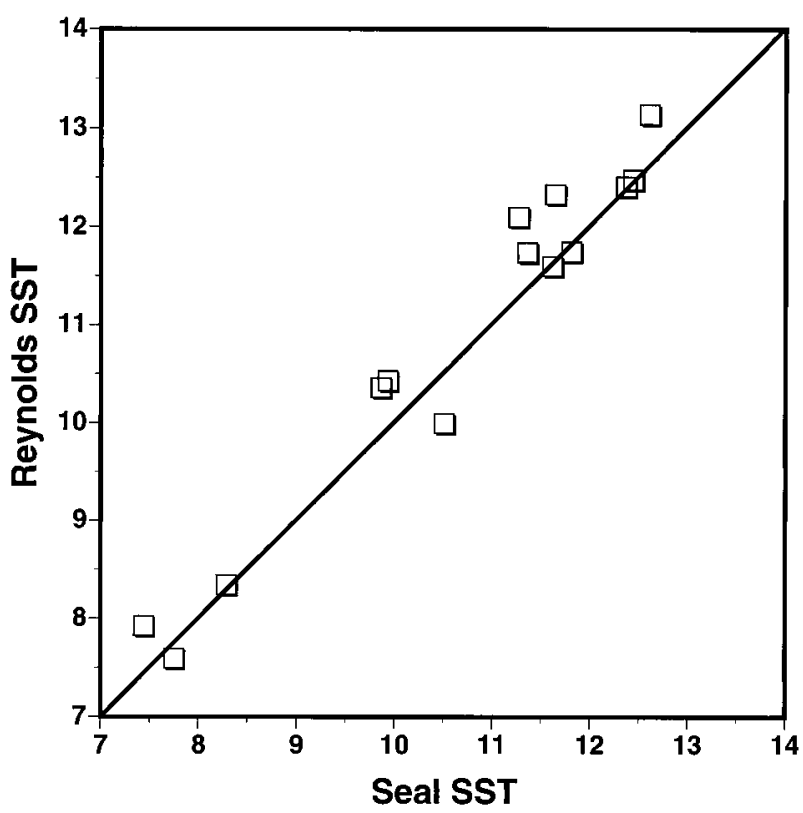

FIG. 8. Comparison of seal-derived SST data with weekly Reynolds surface temperatures. Data are derived by taking the mean surface temperature from the TTDR values within a single week $-1^{\circ}$ square stratum and comparing it with the weekly mean Reynolds value for the same time and location. Data points were taken from throughout the region in which the animals moved (Fig. 2) and represent nine seals from 1998 (for the week ending 3 Mar) and five seals from 1997 (for the week ending 1 Apr).

Within these time-area strata, all coincident data from seals and GTSPP profiles were compared by differencing average values at 5-m depth intervals between the surface and $500 \mathrm{~m}$. After removing flagged profile data from the GTSPP series, there were a total of $121^{\circ}-1$-month strata with both seal and XBT data. The XBT data typically consisted of one or two profiles being compared with a large amount of autonomous pinniped bathythermograph (APBT) data. Differences ranged between $-0.91^{\circ}$ and $1.30^{\circ} \mathrm{C}$, with average 0.02 and standard deviation 0.39 . Although data were variable, there appeared to be patterns; from the surface to $90 \mathrm{~m} \mathrm{XBT}$ values tended to be warmer, whereas below $300 \mathrm{~m}$ XBT values tended to be cooler (Fig. 9). We also compared Reynolds surface temperatures for these same locations and times. Mean surface temperatures were $10.28^{\circ}, 10.50^{\circ}$, and $10.95^{\circ} \mathrm{C}$ for APBTs, Reynolds, and XBTs, respectively. This is consistent with the comparison with the Reynolds surface data with corresponding APBT data (Fig. 8).

It is useful to compare the cost effectiveness of the temperature profiles obtained in this study with more traditional profiles, such as XBTs. Even ignoring the costs for vessel time, temperature profiles from northern elephant seals come at low cost. Personnel costs for tagging and recovery are approximately $16 \mathrm{~h}$ per deployment on northern elephant seals. This includes programming, packaging, deployment, and recovery of the

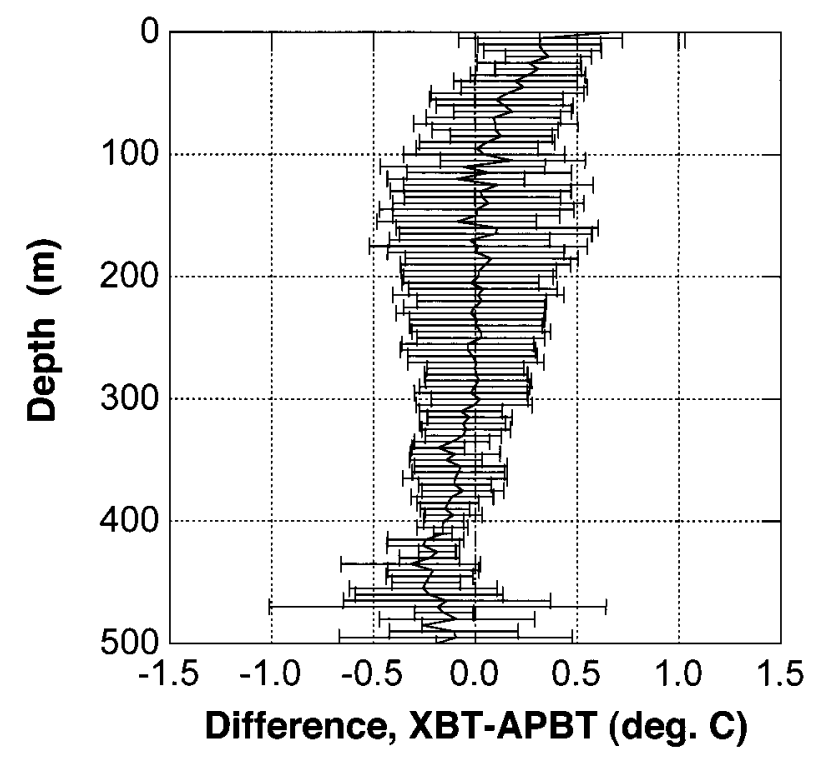

FIG. 9. Comparison of seal-collected (APBT) data with GTSPP profile data. Comparisons are based upon the two data sources in coincident time-area strata $\left(1^{\circ}\right.$ squares by month) at $5-\mathrm{m}$ depth intervals between the surface and $500 \mathrm{~m}$. The values on the $x$ axis represent the difference between GTSPP and APBT values at each depth; error bars represent $95 \%$ confidence intervals.

tags. In addition, approximately $4 \mathrm{~h}$ per deployment are spent in data handling. Given the nine animals in this study and the number of profiles, the personnel costs are trivial-0.02 min per APBT or 0.88 min per APBT with corresponding ARGOS fix. This is certainly less than the cost of handling associated with XBT casts. The financial costs are also relatively low. For the animals used in this study, the ARGOS PTT cost $\$ 2250$, the TTDR cost \$2000, and each ARGOS fix cost \$5.40. This translates to a cost for the nine animals in this study of \$0.67 per APBT or \$34.31 per APBT with corresponding ARGOS fix. All of these values have been discounted for the average $92 \%$ recovery rate for northern elephant seals (LeBoeuf et al. 2000) and for instrument failure, but do not take into account the fact that the instruments can be reused after recovery. Compared to current costs for an XBT, the APBTs are highly cost effective.

\section{d. Seal data in the WOD}

A total of 75665 APBT profiles were defined as described above and stored in the WOD (Fig. 10). The data were minimally processed to preserve as much of the original data resolution as possible. Ancillary information (e.g., information on the temperature sensor, the ARGOS signal quality, and the time offset from the previous and next ARGOS fixes) were stored to allow the WOD user to process and tailor the data to a resolution that fits their needs. As an example, a user could select only upcast profiles, or those taken within $1 \mathrm{~h}$ of 


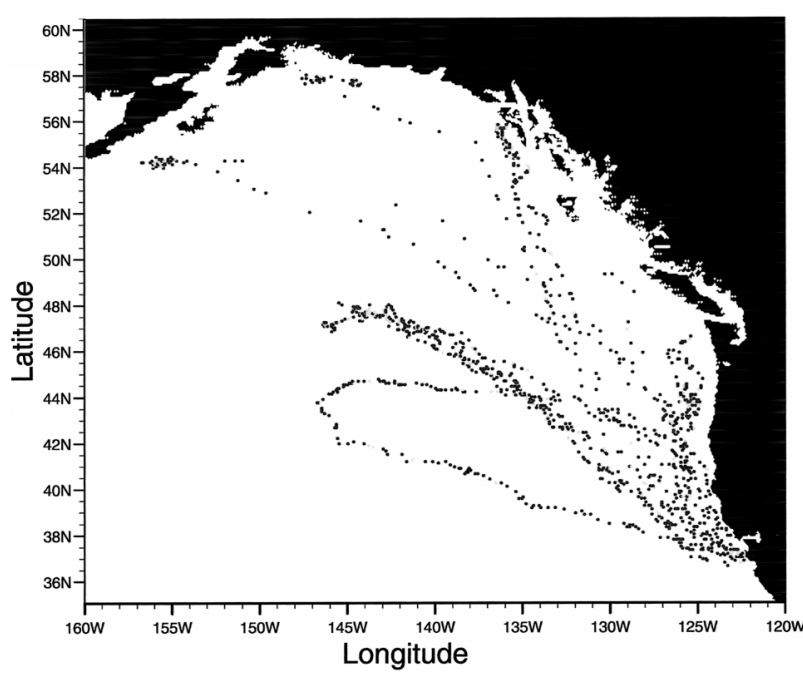

FIG. 10. Distribution of APBTs added to the WOD. Shown are locations of those profiles with an associated ARGOS location, representing 1478 APBTs. The total number of profiles added is 75665 .

an ARGOS fix; 1478 profiles had an associated ARGOS fix (Fig. 10). The average vertical distance between adjacent data points in these profiles is $30.0 \mathrm{~m}$ for females and $20.1 \mathrm{~m}$ for males. These data will be available in the next release, WOD-2001.

One quality control check included comparisons of the seal TTDR temperatures with the WOD98 annual, seasonal, and monthly climatologies. This essentially checks the temperature values against the WOD98 analyzed mean value of the entire $1^{\circ} \times 1^{\circ}$ grid. If the difference is $>3$ standard deviations from the WOD98 analyzed mean, that observations is deemed a "statistical outlier." If a profile has more than two statistical outliers in it, the entire profile is flagged. Although this is not a foolproof check (i.e., legitimate features can be flagged), it does provide a quick review of the data. Analyses on all the seals showed varying percentages of flagged profiles (Table 3). The seals Storm and Rain are particularly noteworthy, with over $20 \%$ of their profiles flagged. Unlike many of the other females, however, both spent more time near the coast (Fig. 2), where the $1^{\circ}$ WOD9 8 climatologies may be less than optimal. Moreover, the seal Pete was in the same general area a year earlier, and has a very low percentage of flagged profiles. As an El Niño year, 1998 was unusually warm (Lynn et al. 1998), and January through April coastal temperatures were far higher than normal (Schwing and Moore 2000). Because over $99 \%$ of the flagged profiles were at higher (rather than lower) temperature values than the climatological boundaries, these profiles are likely valid.

\section{Summary and conclusions}

This is the first study clearly demonstrating that biological autonomous sampling systems, such as north-
TABLE 3. APBT profiles added to the WOD from the current project. The flags, described in the text, are the percentages of total profiles flagged in the quality control process due to individual temperature records exceeding certain differences from the annual, seasonal, or monthly climatology in WOD98.

\begin{tabular}{lrrrrr}
\hline \hline \multicolumn{1}{c}{ Seal } & Year & $\begin{array}{c}\text { Total } \\
\text { profiles }\end{array}$ & $\begin{array}{c}\text { Annual } \\
\text { flags }\end{array}$ & $\begin{array}{c}\text { Seasonal } \\
\text { flags }\end{array}$ & $\begin{array}{c}\text { Monthly } \\
\text { flags }\end{array}$ \\
\hline Pete & 1997 & 1865 & $0.10 \%$ & $0.10 \%$ & $0.10 \%$ \\
Moose & 1997 & 10612 & $0.20 \%$ & $1.00 \%$ & $0.50 \%$ \\
Bopp & 1997 & 7397 & $1.20 \%$ & $4.20 \%$ & $7.50 \%$ \\
Rain & 1998 & 8379 & $23.40 \%$ & $20.60 \%$ & $20.60 \%$ \\
Storm & 1998 & 2043 & $32.00 \%$ & $28.00 \%$ & $30.10 \%$ \\
Wave & 1998 & 10681 & $18.20 \%$ & $18.30 \%$ & $18.50 \%$ \\
Sun & 1998 & 11620 & $7.40 \%$ & $15.50 \%$ & $15.80 \%$ \\
Gale & 1998 & 11904 & $2.40 \%$ & $1.60 \%$ & $1.60 \%$ \\
Sun2 & 1998 & 11164 & $1.70 \%$ & $3.00 \%$ & $4.50 \%$ \\
\hline
\end{tabular}

ern elephant seals, have the potential to provide oceanographic sampling that is on par, in terms of quality, with other contemporary sampling systems. Using data from migrations from only nine animals over $3 \mathrm{yr}$, we have added nearly 76000 temperature-depth profiles in the northeast Pacific (Fig. 10) to the WOD (Levitus et al. 1998).

The northern elephant seal example shown here represents but one species covering portions of the northeast Pacific Ocean (Fig. 2). Existing tag technologies are allowing new research to understand the distribution, behavior, and ecology of marine animals. Research programs presently exist on a variety of species, including southern elephant seals (Boyd and Arnbom 1991), tunas and billfish (Block et al. 1997), sharks (Sims and Quayle 1998), seabirds (Hunt et al. 1990; Wilson et al. 1998; Tuck et al. 1999; Koudil et al. 2000), and whales (Craig and Herman 2000; Lagerquist et al. 2000). It is likely that such tags will be applied to more marine organisms. As an example, a major scientific undertaking called the "Census of Marine Life" (CoML; Ausubel 1999; see also www.coml.org) views electronic tags as an important new technology (Stone et al. 1999). Two current CoML pilot projects, called "Pacific Ocean Salmon Tracking" and "Tagging of Pacific Pelagics" are focused on use of electronic tags. With continued miniaturization, improvements in sensor technology, and geolocation techniques (Welch and Eveson 1999), more of these data will become appropriate for use in oceanographic studies.

Implementation of expanding ocean observation systems will require greater availability of oceanographic data from varied sources. Already, vessel of opportunity programs (Emery et al. 1997), profiling floats (Roemmich and Owens 2000), and autonomous underwater vehicles (Bellingham et al. 2000) are improving ocean data. The procedures we have outlined in this study may serve as a model for data recorded from tagged animals when it meets the requisite criteria for data quality and geolocation. This innovative approach, however, can serve as an important adjunct to other means of col- 
lecting oceanographic data to meet community goals of improving ocean data availability.

Acknowledgments. The research collecting the original northern elephant seal data was supported by the Office of Naval Research, the ATOC research program through the Scripps Institution of Oceanography (D. Costa, Principal Investigator). Additional funding to support this extension of that research came from NOAA's ESDIM program and the Institute of Marine Sciences Packard Endowment for Ocean Research and Technology. We thank Lynn deWitt and James Ganong for assistance with certain data handling and Tim Boyer, Lynn deWitt, Scott Woodruff, and three anonymous reviewers for comments on earlier drafts of the manuscript.

\section{REFERENCES}

Aiken, J., R. Pollard, R. Williams, G. Griffiths, and I. Bellan, 1999: Measurements of the upper ocean structure using towed profiling systems. Large Marine Ecosystems of the Pacific Rim: Assessment, Sustainability, and Management, K. Sherman and Q. Tang, Eds., Blackwell Science, Inc., 346-362.

Ausubel, J. 1999: Toward a Census of Marine Life. Oceanography, 12, 4-5.

Bellingham, J. G., K. Streitlien, J. Overland, S. Rajan, P. Stein, J. Stannard, W. Kirkwood, and D. Yoerger, 2000: An Arctic basin observational capability using AUVs. Oceanography, 13, 6470.

Block, B. A., J. E. Keen, B. Castillo, H. Dewar, E. V. Freund, D. J. Marcinek, R. W. Brill, and C. Farwell, 1997: Environmental preferences of yellowfin tuna (Thunnus albacares) at the northern extent of its range. Mar. Biol., 130, 119-132.

- H. Dewar, C. Farwell, and E. D. Prince, 1998: A new satellite technology for tracking the movements of the Atlantic bluefin tuna. Proc. Natl. Acad. Sci. U.S.A., 95, 9384-9389.

Boehlert, G. W., Ed., 1997: Application of acoustic and archival tags to assess estuarine, nearshore, and offshore habitat utilization and movement by salmonids. NOAA Tech. Memo. NOAA-TMNMFS-SWFSC-236, 62 pp.

Boyd, I. L., and T. Arnbom, 1991: Diving behavior in relation to water temperature in the southern elephant seal: Foraging implications. Polar Biol., 11, 259-266.

Brannas, E., H. Lundqvist, E. Prentice, M. Schmitz, K. Brannas, and B. S. Wiklund, 1994: Use of the passive integrated transponder (PIT) in a fish identification and monitoring system for fish behavioral studies. Trans. Amer. Fish. Soc., 123, 395-401.

Brill, R. W., G. H. Balazs, K. N. Holland, R. K. C. Chang, S. Sullivan, and J. C. George, 1995: Daily movements, habitat use, and submergence intervals of normal and tumor-bearing juvenile green turtles (Chelonia mydas $\mathrm{L}$ ) within a foraging area in the Hawaiian Islands. J. Exp. Mar. Biol. Ecol., 185, 203-218.

Campagna, C., A. L. Rivas, and M. R. Marin, 2000: Temperature and depth profiles recorded during dives of elephant seals reflect distinct ocean environments. J. Mar. Syst., 24, 299-312.

Conkright, M. E., and Coauthors, 1998: World Ocean Database 1998 CD-ROM: Data set documentation and quality control. User's Manual, National Oceanographic Data Center, Silver Spring, MD, $117 \mathrm{pp}$.

Costa, D. P., 1993: The secret life of marine mammals: Novel tools for studying their behavior and biology at sea. Oceanography, 6, $120-128$

Craig, A. S., and L. M. Herman, 2000: Habitat preferences of female humpback whales Megaptera novaeangliae in the Hawaiian Is- lands are associated with reproductive status. Mar. Ecol.: Prog. Ser., 193, 209-216.

Emery, W. J., K. Cherkauer, B. Shannon, and R. W. Reynolds, 1997: Hull-mounted sea surface temperatures from ships of opportunity. J. Atmos. Oceanic Technol., 14, 1237-1251.

Folland, C. K., and D. E. Parker, 1990: Observed variations of sea surface temperature. Climate-Ocean Interaction, M. E. Schlesinger, Ed., Kluwer Academic, 21-52.

Hunt, G. L., Jr., N. M. Harrison, and R. T. Cooney, 1990: The influence of hydrographic structure and prey abundance on foraging of least auklets. Stud. Avian Biol., 14, 7-22.

Koudil, M., J.-B. Charrassin, Y. Le Maho, and C.-A. Bost, 2000: Seabirds as monitors of upper-ocean thermal structure. King penguins at the Antarctic polar front, east of Kerguelen sector. $C$. R. Acad. Sci. Paris, Ser. III, 323, 377-384.

Lagerquist, B. A., K. M. Stafford, and B. R. Mate, 2000: Dive characteristics of satellite-monitored blue whales (Balaenoptera musculus) off the central California coast. Mar. Mammal Sci., 16, 375-391.

Le Boeuf, B. J., and D. E. Crocker, 1996: Diving behavior of northern elephant seals: Implications for predator avoidance. Great White Sharks, The Biology of Carcharodon Carcharias, A. P. Klimley and D. G. Ainley, Eds., Academic Press, 193-206.

— , P. A. Morris, S. B. Blackwell, D. E. Crocker, and D. P. Costa, 1986: Diving behavior of juvenile northern elephant seals. Can. J. Zool., 74, 1632-1644.

_ D. E. Crocker, D. P. Costa, S. B. Blackwell, P. M. Webb, and D. S. Houser, 2000: Foraging ecology of northern elephant seals. Ecol. Monogr., 70, 353-382.

Levitus, S., and Coauthors, 1998: Introduction. Vol. 1, World Ocean Database 1998, NOAA Atlas NESDIS, 346 pp.

Lutcavage, M. E., R. W. Brill, G. B. Skomal, B. C. Chase, and P. W. Howey, 1999: Results of pop-up satellite tagging of spawning size class fish in the Gulf of Marine: Do North Atlantic bluefin tuna spawn in the mid-Atlantic? Can. J. Fish. Aquat. Sci., 56, 173-177.

Lynn, R. J., and Coauthors, 1998: The state of the California Current, 1997-1998: Transition to El Niño conditions. Calif. Coop. Oceanic Fish. Invest., 39, 25-49.

McCafferty, D. J., I. L. Boyd, T. R. Walker, and R. I. Taylor, 1999: Can marine mammals be used to monitor oceanographic conditions? Mar. Biol., 134, 387-395.

McConnell, B. J., C. Chambers, K. S. Nicholas, and M. A. Fedak, 1992: Satellite tracking of grey seals (Halichoerus grypus). J. Zool., London, 226, 271-282.

Polovina, J. J., D. R. Kobayashi, D. M. Parker, M. P. Seki, and G. H. Balazs, 2000: Turtles on the edge: Movement of loggerhead turtles (Caretta caretta) along oceanic fronts, spanning longline fishing grounds in the central North Pacific, 1997-1998. Fish. Oceanogr., 9, 71-82.

Reynolds, R. W., and T. M. Smith, 1994: Improved global sea surface temperature analyses using optimum interpolation. J. Climate, 7, 929-948.

Roemmich, D., and W. B. Owens, 2000: The Argo project: Global ocean observations for understanding and prediction of climate variability. Oceanography, 13, 45-50.

Roy, C., and R. Mendelssohn, 1998: The development and the use of a climatic database for CEOS using the COADS dataset. Global versus Local Changes in Upwelling Systems, M.-H. Durand et al., Eds. Collection Colloques et Seminaires, Editions de I'Orstom, 27-44.

Schwing, F., and C. Moore, 2000: A year without summer for California, or a harbinger of a climate shift. EOS, Trans. Amer. Geophys. Union, 81, 301, 304-305.

Sims, D. W., and V. A. Quayle, 1998: Selective foraging behaviour of basking sharks on zooplankton in a small scale front. Nature, 393, 460-464.

Stone, G., J. Schubel, and H. Tausig, 1999: Electronic marine animal tagging: New frontier in ocean science. Oceanography, 12, 2427. 
Taillade, M., 1992: Animal tracking by satellite. Wildlife Telemetry: Remote Monitoring and Tracking of Animals, G. Priede and S. Swift, Eds., Ellis Horwood, Ltd., 708 pp.

Tuck, G. N., T. Polacheck, J. P. Croxall, H. Weimerskirch, P. A. Prince, and S. Wotherspoon, 1999: The potential of archival tags to provide long-term movement and behaviour data for seabirds: First results from wandering albatross Diomedea exulans of South Georgia and the Crozet Islands. Еmu, 99, 60-68.

Walker, R. V., and Coauthors, 2000: Diurnal variation in thermal environment experienced by salmonids in the North Pacific as indicated by data storage tags. Fish. Oceanogr., 9, 171186.

Welch, D. W., and J. P. Eveson, 1999: An assessment of light-based geoposition estimates from archival tags. Can. J. Fish. Aquat. Sci., 56, 1317-1327.

Wilson, R. P., B. M. Culik, P. Kosiorek, and D. Adelung, 1998: The over-winter movements of a chinstrap penguin (Pygoscelis antarctica). Polar Rec., 34, 107-112. 